\title{
Safety of soy-derived phosphatidic acid supplementation in healthy young males
}

\author{
Joshua E. Dudeck', Jordan M. Joy ${ }^{1}$, Ryan P. Lowery ${ }^{1}$, Eduardo O. De Souza², Ralf Jäger ${ }^{3}$, Sean A. McCleary ${ }^{1}$, \\ Stephanie M.C. Wilson ${ }^{4}$, Martin Purpura ${ }^{3}$, Jacob M. Wilson ${ }^{1 *}$ \\ From International Society of Sports Nutrition: 10th Annual ISSN Conference and Expo \\ Colorado Springs, CO, USA. 14-15 June 2013
}

\section{Background}

The mammalian target of rapamycin (mTOR) has been shown to regulate rates of muscle protein synthesis, and one novel nutritional activator of mTOR is the phospholipid Phosphatidic Acid (PA). We have recently found that PA supplementation over 8 weeks of resistance training augmented responses in skeletal muscle hypertrophy and strength. However, we are unaware of research investigating the safety of PA in human subjects. Therefore the purpose of this study was to investigate the effects of 8 weeks of $750 \mathrm{mg}$ per day of PA supplementation on safety parameters in healthy college aged males.

\section{Methods}

Twenty-eight healthy, college aged male subjects $(21 \pm 3$ years of age, bodyweight of $76 \pm 9 \mathrm{~kg}$, and height of $176 \mathrm{~cm} \pm 9 \mathrm{~cm}$ ) participated in this study. Subjects were equally divided into experimental and control conditions. The experimental condition (EXP) received $750 \mathrm{mg}$ of soy-derived PA (Mediator ${ }^{\mathrm{TM}}$, Chemi Nutra, White Bear Lake, $\mathrm{MN})$, while the control condition $(\mathrm{CON})$ received a visually identical placebo (rice flour). Measures of cardiovascular, kidney, and liver function were analyzed with a full CMP and CBC prior to and 8 weeks following supplementation. This analysis included: total, high density, and low density lipoproteins, blood glucose, blood urea nitrogen, creatinine, eGFR, $\mathrm{Na}, \mathrm{K}, \mathrm{Cl}, \mathrm{CO} 2, \mathrm{Ca}$, protein, albumin, globulin, albumin:globulin ratio, total bilirubin, alkaline phosphatase, aspartate aminotransferase, and alanine aminotransferase. In addition a sample of urine was submitted for analysis of urine specific gravity and $\mathrm{pH}$. A $2 \times 2$ repeated measures ANOVA was used to determine group, time, and group $\mathrm{x}$ time interactions. A Tukey post-hoc was used to locate differences.

\section{Results}

There were no differences at baseline in blood chemistry and hematology between the CON and EXP supplemented groups. Additionally no differences were observed in urinalysis values between the groups. Moreover no group, or group $\mathrm{X}$ time effects were found following 8 weeks of supplementation.

\section{Conclusions}

Soy-derived PA is a safe nutritional supplement for healthy college aged subjects if taken up to a dosage of $750 \mathrm{mg}$ over an eight week period.

\section{Acknowledgements \\ Supported by Chemi Nutra, White Bear Lake, MN, USA.}

\section{Authors' details}

'Department of Health Sciences and Human Performance, The University of Tampa, Tampa, FL, USA. ${ }^{2}$ Laboratory of Neuromuscular Adaptations to Strength Training, School of Physical Education and Sport, University of São Paulo, São Paulo, Brazil (EDS). ${ }^{3}$ Increnovo LLC, 2138 E Lafayette PI, Milwaukee, WI, USA. ${ }^{4}$ Department of Nutrition, IMG Performance Institute, IMG Academy, Bradenton, FL, USA.

Published: 6 December 2013

\section{doi:10.1186/1550-2783-10-S1-P6}

Cite this article as: Dudeck et al:: Safety of soy-derived phosphatidic acid supplementation in healthy young males. Journal of the International Society of Sports Nutrition 2013 10(Suppl 1):P6.

\footnotetext{
* Correspondence: jmwilson@ut.edu

'Department of Health Sciences and Human Performance, The University of Tampa, Tampa, FL, USA

Full list of author information is available at the end of the article
} 